\title{
Using the Positive Self Model in Improving Skill Performance Level and Cognitive Achievement in Wrestling among Physical Education Faculty Students
}

\author{
Ehab Mohammed Al Sadek Hassan*
}

The purpose of this research was to investigate the effectiveness of using the Positive self Model in improving the skill performance and cognitive achievement levels related to the wrestling skills (Bear hug to Backast, under arm hold to throw over the back, waist turnover, reverse Body lift) among physical Education Faculty students. The sample of the research was selected randomly from the second-year students of physical Education in Faculty for boys in Zagazig. It included (40) students. The researcher used (10) students as a standardization sample Hence, the basic sample become thirty students who were divided into two groups; experimental group $(n=15)$ and control group $(n=15)$. The researcher used the assessment of evaluators by an evaluating form of skill performance level. And also he used a written test for evaluating the cognitive achievement, in addition to the physical tests. The main results of the research showed that there were statistically significant differences between the experimental and control groups in the post- test of the skill performance and cognitive achievement levels in favor of the experimental group. Since the learning by using the positive self Model proved to be effective in improving students' levels of skills and cognitive domains as well.

\section{Introduction}

$I^{1}$ $\mathrm{n}$ wrestling, the ability of learning motor skills is considered to be a kind of compound abilities based on co-ordination which enables the wrestler to learn and improve the technical skills. The duration required to master these skills is considered to be a criterion of motorlearning considering the individual's physical abilities, the difficulty of the skill and the methods used in training.(Gable, 1999).

The motor learning and the perfection of skills is entirely related to understanding and using the information and different scientific facts of the cognitive domain such as the rules of competitions,

*Lecturer, Department of Theories and Applications of Fights and Individual Sports, Faculty of Physical Education for Boys, Zagazig University, Egypt. the basic information about the human body and the demands of the perfect technical performance of different skills.(Keith, 1990).

The cognitive achievement presents an important aspect in wrestling associated with the skill performance and the outputs of the instructional process in general. The cognitive aspect in wrestling includes different topics such as tactics, techniques, the international rules of wrestling, the history and procedures of safety and security which can be measured by using written tests designed by the instructor. The written test included different objective questions (True - false questions, matching, identification, completion, arrangement). And chosen test can be considered as an important indicator of instructional achievement and the products of instruction in wrestling.

Wrestling is distinguished by the variety and multiplicity in its skills and the difficulty of 
some technician skills performance. That is the reason why the beginners refrain from practicing wrestling. Consequently, the specialists of wrestling started to think about the development of methods and aids associated with learning wrestling skills continuously . (German \& Hanley, 1983)

Halliwell (1990) stated that one of the most modern techniques of instruction technology is Positive self Model which can be used in the sporting training domain.

The use of modeling has been studied as an effective teaching tool in many realms (Bradly, 1993; Feltz, 1982; Hall \& Erffmeyer, 1983). Bradley (1993) found that over time positive self-modeling can have a positive effect on the performance of basketball players. Fetlz (1982) reported that participants who had twelve demonstrations had higher form scores than the control group on a Bachman-ladder test. Hall and Erffmeyer (1983) reported an improvement in foul shot performance when modeling with visuo-motor behavior rehearsal (VMBR) was used. The results showed that there was a significant improvement difference for the group who received modeling compared with the group that did not (Hall \& Erffmeyer, 1983). Gray (1990) showed that modeling combined with visuo-motor behavior rehearsal can lead to improvements in racquetball performance. Also it has been shown that modeling can lead to improvement in self-confidence of the participant (Vealey, Hayashi, Garner-Holman \& Giacobbi, 1998; Weinberg, Grove, and Jackson, 1992).

The researcher found out through teaching wrestling course to the students at the physical Education Faculty, that the motor learning of different skills of wrestling, raising the performance and mastery level depends greatly on the motor conceiving of the compound performance of these motions and also the

student's knowledge of his performance, to what extent his performance is near or far from the optimal performance of the motor skills in wrestling. Therefore, the researcher found that reinforcement of training process, by using the positive self Model, will enable the student to watch his performance by using videotap and that will provide the student with a great deal of experience. This experience supports him to benefit from the progress in his performance level and the remediation of the errors with regard to the optimal performance of skills. Furthermore, the positive self Model provides the student with the feedback, which can be followed by reinforcement, and helps the students with his performance orientation soundly. Particularly, if that is related to the consolidation of cognitive domains associated with motor-skill performance of different motions.

Hence, this matter reflects on the qualitative improvement of the motor performance level and also the cognitive domain related to it. So, the results of the instructional process will become better.

However, there have been very few studies which assess the effectiveness of self-modeling as a performance enhancer in wrestling .

\section{Purpose of the study}

The purpose of this study was to investigate the use of videotaped self modeling of some wrestling skills (Bear hug to Backast, under arm hold to throw over the back, waist turnover, reverse Body lift). Supplementary investigation examined the skill performance and cognitive achievement levels of the participants.

\section{Hypotheses of the study}


- there are statistical significant difference of skill performance level and cognitive achievement variables between the pre and the post-test of the experimental group in favor of the post test.

- There are statistical significant differences of skills performance level and cognitive achievement variables between the experimental and the control groups on the post-test in favor of the experimental group.

\section{Methods}

\section{Sample of the research :}

The sample of the research was selected randomly from the second-year students of physical Education Faculty in Zagazing 2010$2011(n=327)$. The researcher chose a random sample $(n=40)$ students. The selection criteria for the subjects were :
- They attend classes regularly.

- The distribution normality of the research sample is related to the growth variables and he physical measurements.

The researcher made sure of the distribution normality of the sample on some variables that might have had an effect on the experimental variables such as variables of growth (age, height, weight) and some physical measurements associated with the skills which were under research as the table (1) shows.

He used $(n=10)$ students as a standardization sample to make the validity and reliability testing and to make sure of the clarity of the tests conditions also to apply an instruction unit. Thus, the basic sample became $(n=30)$ students who were divided into two groups; experimental group $(\mathrm{n}=15)$ and Control group $(\mathrm{n}=15)$

- All of them are studying the same skills of the research .

- They have the same instructor.

Table (1): The mathematical average, the standard deviation, skewness coefficient of the research sample of some chosen variables.

\begin{tabular}{|c|c|c|c|c|c|c|}
\hline \multicolumn{2}{|l|}{ Variables } & $\begin{array}{c}\text { Unit of } \\
\text { measurement }\end{array}$ & $m$ & $\sigma$ & Median & $\begin{array}{l}\text { Skewness } \\
\text { coefficient }\end{array}$ \\
\hline \multirow{3}{*}{ Growth } & Age & Year & 19.91 & 0.14 & 19.75 & 0.12 \\
\hline & Height & $\mathrm{Cm}$ & 169.40 & 0.82 & 170.00 & -1.55 \\
\hline & Weight & $\mathrm{Kg}$ & 76.38 & 0.86 & 77.00 & -0.31 \\
\hline \multirow{5}{*}{$\begin{array}{c}\text { physical } \\
\text { measurements }\end{array}$} & Grip strength & $\mathrm{Kg}$ & 39.88 & 0.39 & 40.00 & -0.46 \\
\hline & Legs muscles strength & $\mathrm{Kg}$ & 142.88 & 0.41 & 143.00 & 0.28 \\
\hline & Back Lit Strength & $\mathrm{Kg}$ & 126.68 & 0.53 & 125.75 & 0.91 \\
\hline & $\begin{array}{l}\text { Back bone flexibility } \\
\text { (vertical) }\end{array}$ & $\mathrm{Cm}$ & 57.57 & 0.22 & 57.20 & 0.03 \\
\hline & $\begin{array}{l}\text { Back bone flexibility } \\
\text { (horizontal) }\end{array}$ & $\mathrm{Cm}$ & 69.80 & 0.30 & 69.50 & 0.06 \\
\hline
\end{tabular}

Table (1) shows that skewness coefficients ranged from (+3) to (-3) in all variables. That refers to the distribution normality of research sample relating to these variables. 


\section{Measures}

\section{Cognitive achievement test :}

The researcher prepared a cognitive test about the technician performance of wrestling skills under the research (Bear hug to Backast, under arm hold to throw over the back, waist turnover, reverse Body lift) and also the cognitions and the information associated with them. The researcher analyzed the cognitive tests of prior studies. The researcher depended on scientific approach in preparing them by using techniques for phrasing the questions. So, the researcher used three methods for phrasing the test, depending on the scientific references. He used essay questions; completion questions and true false questions. The preliminary test included ten items and were presented to know the specialists opinions about their clarity, for phrasing besides modification, omitting and adding some suitable sentences.

The specialists' approval percentage about all items of the suggested test ranged from $(90 \%$ to $100 \%)$. The researcher implemented the suggested cognitive achievement test on the standardization sample $(n=10)$ students. After implementation, the researcher checked the students' answers and wrote down the students' marks. And also he put them in a descending order according to the total mark of each student. He chose $27 \%$ of highest marks which presented the excellent students. And also he chose $27 \%$ of the lowest marks which presented the weak students to calculate the difficulty, facility and discrimination coefficients.

Hence, the difficulty coefficients values ranged from 0.30 to 0.66 and facility coefficients values ranged from 0.34 and 0.70 and discrimination coefficients reached more than (0.30). So, all the test items were accepted according to their coefficients. And also the researcher used validity of internal coordination to calculate the correlation coefficient between the mark of each item and the total mark of the test.
The correlation coefficients ranged from 0.811 to 0.963 . And to calculate the reliability, the researcher implemented the test on the standardization sample and then he repeated it again after an interval period (about 15 days) after the first test. And he calculated the correlation coefficient between the two applications and the value was 0.970 . Hence, this was statistically significant and refereed to the stability of the suggested test.

\section{Skill performance Evaluation form:}

The researcher designed skill performance evaluation form of the skills under the research. The researcher Specified evaluation criteria to make the form objective and also based on the items of the international rules of wrestling. Then he presented and modified it on the basis of the specialists' opinions. The research agreed to $80 \%$ of their opinions at least. And he filmed the technician performance by using video Camera Benq Del 1020 and he presented the acts of performance to three (3) evaluators at the same time so that they could assess the students' performance level through skill level Evaluation from.

The selection criteria for the (3) evaluators were.

- they must be specialists in teaching wrestling with 10 years of experience at least.

- They must evaluate the performance through the evaluation form.

- They must have phD at least.

- The mark is given according to the majority $2: 1$.

\section{Procedures :}

The researcher implemented the pre-test of skill performance cognitive achievement on the experimental and the control groups from $9 / 11 / 2010$ to $10 / 11 / 2010$. 
The researcher used the experimental method with pre-post test for two groups, experimental group and control group. The instructional program was implemented by using the positive self. Model on the experimental group for 8 weeks, 2 units a week, from 12-11-2010 to 8-12011 and the duration of teaching a unit is (45) minutes presented the actual time for the actual instruction.

The researcher used the positive self Model by using video camera Benq Del 1020 then he transformed the film of student's performance into CD through ATI card by using T.V. tuner. After that, the film came out on Data show. This happened many times according to the difficulty level of each skill.

The post-test was implemented on the experimental and the control group with the same condition of the pre-test from 9-1-2011 to 10-1-2011.

\section{Design :}

The researcher used the experimental design with pre-post test of two groups an experimental and control groups.

\section{The independent variable:}

The independent variable was using the videotaped positive self modeling as a teaching tool through an instructional programme for 8 weeks.

The dependent variables :

- The performance level of wrestling skills(Bear hug to Backast, under arm hold to throw over the back, waist turnover, reverse Body lift) represented by student's marks given by(3) evaluators through an evaluation form of (15) marks .

- The cognitive achievement represented by student's marks in a written test of (40) marks.

\section{Analysis of data:}

In order to achieve the purpose of the study and to test the hypothes about the positive influence of the instructional programme using positive self model as an independent variable on the skill performance level and cognitive achievement of wrestling skills as dependent variables .

The researcher used the mathematical average, standard deviation, median and skewness coefficient to make sure of the sample distribution under the normal curve of age, height, weight, physical tests variables. He also used the correlation coefficient to calculate the validity and reliability of physical and cognitive achievement tests.

Besides, he used the (T) Test to calculate the statistical significant differences between the means of pre-post test for the experimental and control groups. And so the significant difference between the two groups in the pre-post tests of skill performance and cognitive achievement levels separately. In addition, the researcher calculated the progress percentages to investigate the progress that has been achieved by using the positive self Model relating to the level of skill performance and cognitive achievement.

\section{Results :}

There were no statistical significant differences of variables between the experimental and control groups in the pre-test. That refers to the equivalence between the two groups in skill performance and cognitive achievements levels.

Table (2): The Standard deviation, the mathematical average and T-value between the pre-test, and post-test and progress level of the control group in skill performance and cognitive achievement level.

$n=15$ 
Ehab Mohammed Al Sadek Hassan

\begin{tabular}{|l|c|c|c|c|c|c|c|}
\hline \multirow{2}{*}{ Variables } & \multicolumn{2}{|c|}{ Pre-Test } & \multicolumn{2}{c|}{ Post Test } & \multirow{2}{*}{ Difference } & T-value & $\begin{array}{c}\text { Percentage } \\
\text { of progress } \\
\%\end{array}$ \\
\cline { 2 - 8 } & $m$ & $\sigma$ & $M$ & $\sigma$ & & \\
\hline Skill performance level & 8.26 & 0.26 & 10.53 & 0.24 & 2.27 & $4.18^{*}$ & 27.48 \\
\hline Cognitive achievement & 20.00 & 0.77 & 29.00 & 0.59 & 9.00 & $6.58^{*}$ & 45.00 \\
\hline
\end{tabular}

Level of significance $(\propto)$ at $\mathbf{0 . 0 5}$

Table (2) shows that there were statistical significant differences of skill performance and cognitive achievements variables between the pre-test and the post-test. In favor of the post-test. And also there were progress percentages of variables in favor of the post -test.

Table (3): The standard deviation, the mathematical average and T-value between the pre-test, post-test and progress level of the experimental group in skill performance and cognitive achievement level $n=15$

\begin{tabular}{|l|c|c|c|c|c|c|c|}
\hline \multirow{2}{*}{ Variables } & \multicolumn{2}{|c|}{ Pre-Test } & \multicolumn{2}{c|}{ Post Test } & \multirow{2}{*}{ Difference } & T-value & $\begin{array}{c}\text { Percentage } \\
\text { of progress } \\
\%\end{array}$ \\
\cline { 2 - 8 } & $\mathbf{m}$ & $\sigma$ & $\mathbf{M}$ & $\sigma$ & & & $7.29 *$ \\
\hline Skill performance level & 8.40 & 0.34 & 14.27 & 0.25 & 5.87 & 69.88 \\
\hline Cognitive achievement & 20.47 & 0.86 & 38.27 & 0.42 & 17.80 & $13.91 *$ & 86.96 \\
\hline
\end{tabular}

Level of significance ( $\propto$ ) at $\mathbf{0 . 0 5}$

Table (3) Shows that there were statistical significant differences of skill performance and cognitive achievements variables between the pre-test and the post-test in favor of the post test and also there were progress percentages of variables in favor of the post test.

Both of control group $(n=15)$ and experimental cognitive achievement in the control group the group $(n=15)$ improved significantly from pre to $(\mathrm{T})$ value was $4.18^{*}$ on skill performance level post-test on both variables. In the experimental and it was $6.58^{*}$ on cognitive achievement. group the (T) value was $7.29 *$ on skill These values are statistically significant (table 2 performance level and it was $13.91^{*}$ on ,3).

Table (4): the Standard deviation, the mathematical average and (T) value between the experimental and control groups on the post-test of skill performance and cognitive achievement

$$
n 1=n 2=5
$$




\begin{tabular}{|l|c|c|c|c|c|}
\hline \multirow{2}{*}{ Variables } & \multicolumn{2}{|c|}{ Experimental group } & \multicolumn{2}{c|}{ Control group } & \multirow{2}{*}{ (T) value } \\
\cline { 2 - 6 } & $\boldsymbol{m}$ & $\sigma$ & $\boldsymbol{m}$ & $\sigma$ & $40.38^{*}$ \\
\hline Skill performance level & 14.27 & 0.25 & 10.53 & 0.24 & $47.89 *$ \\
\hline Cognitive achievement & 38.27 & 0.42 & 29.00 & 0.59 & \multirow{2}{*}{} \\
\hline
\end{tabular}

Level of significance $(\propto)$ at 0.05

There were statistical significant differences of skill performance level and cognitive achievement variables between the experimental and control groups on the post - test in favor of the experimental group (Table 4).

There was a superiority of the experimental group on the control group in progress percentages. since the progress percentages of control group were $27.48 \%$ in the level of skill performance whereas they were $69.00 \%$ of the experimental group. And the progress percentages of the control group in the cognitive achievement were $45.00 \%$ whereas $86.96 \%$ of the experimental group. (Table 2,3 ).

\section{Discussion}

This research aims to perform an experiment designed to test the efficiency of the positive self model on skill and cognitive learning among boys in physical education, specifically in wrestling. The research central purpose is to investigate the use of videotaped self modeling of some wrestling skills. Supplementary investigation examined the skill performance and cognitive achievement levels of the participants. According to the purpose and hypotheses of the research. The results will be interpreted as follow :

Table (2) illustrates that there were statistical significant differences between the pre and post tests of the control group in favor of the post test concerning the level of skill performance and cognitive achievement.

The researcher attributed that to the performance repetition and much training that resulted in relative improvement of skill performance. The control group were exposed to the same instructional content with regard to the instructional methods, the exercises of physical performance and the theoretical explanation of the course except for using the positive self model. Consequently, there was relative improvement in the performance of skills under the research and also the cognitive achievement of the control group. Yet, this improvement was less than the improvement of experimental group that was achieved deliberately by consolidation of the instructional process by using the positive self Model during the implementation of the suggested instructional programme.

This result was related with cooper (2003) who mentioned that the repetition of orientated instructional activities for the students increased the student's motor achievement and productivity rate through the motor recalling of what has been done in the instructional situation for correction of the technical errors relating to the motor-skill performance.

Jensen \& Fisher (1979) reported that the repetition of performance improves the skill as well as effectiveness of performance.

Table (3) shows that there were statistical significant differences of skill performance level and cognitive achievement variables between the pre - test and the post - test in the experimental group in favor of the post test.

The researcher considers this result can be attributed to using of the positive self Model during the controlled and deliberate instruction 
process by using designed instructional program for this purpose. That led to improvement performance level of skills under the research because of the student's positive and self-vision to himself many times by using the Data show as his vision of the optimal performance model enabled him to chose the optimal performance and omitting the wrong one. Besides, the student deepened his comprehension of correct performance demands. Thus, his conceiving of self- performance of motor - skills resulted in increase in motor - skills mastery.

And also, using the positive self Model provided the students with a part of experience and feedback which participated clearly in the performance orientation, more fruitfully. That is to say, the use of positive self Model can help students become more aware of errors and their nature so they can monitor them in the future. In addition, student can monitor his progress by himself.

In this connection, Bradly (1993) mentioned that the difference in performance between the positive modeling and negative modeling was significant. This suggests that, over time, positive self-modeling has an effect on performance more than negative self-modeling does. Male intramural basketball players were participants in this study which examined the effects of self-modeling and goal-setting on self-efficacy and performance (Bradley, 1993).

Dowrick (1999) reviewed the literature on selfmodeling. It was found that the most successful use of self-modeling in sport occurred in activities not previously performed successfully. Thus, they used a feedforward design (Dowrick, 1999).

So this result prove the first hypothes of the study. That there are statistical significant differences of skill performance level and cognitive achievement variables between the pre and the post test of the experimental group in favor of the post test.

Table (4) shows that there were statistically significant difference between the experimental and control group on the post - test of skill performance and cognitive achievement level in favor of the experimental group.

The tables (2) \& (3) Show that there were progress percentages in favor of the post test to both groups in the level of skill performance and cognitive achievement. The same tables also showed that there was a superiority of the experimental group on the control group in progress percentages since the progress percentages of control group were $27.48 \%$ in the level of skill performance whereas they were $69.00 \%$ of the experimental group. And the progress percentages of the control group in the cognitive achievement were $45.00 \%$ whereas $86.96 \%$ of the experimental group.

The researcher interpreted that these results can be attributed to the instructional process in which the motor learning is limited to the instructional methods practice of motor skill without using the most modern teaching technology. And also, the theoretical explanation through lectures doesn't lead to sufficient instructional products and achievement if they are compared to the instructional products based on the positive self Model by using the aids of filming and data show. Also, by using intended and effective instructional program which makes possible for the motivation, feedback and self-evaluation.

In addition, the consolidation of the information and cognitions practically and the link between them and the demands of the optimal performance led to the experimental group superiority.

This result was related with Knapczyk (1991) who examined the effects of modeling on 
question asking and question answering. The results of the study indicated that videotaping segments for the class and using tem to create opportunities for modeling, rehearsal, and feedback were effective strategies for facilitating generalization of performance" (Knapczyk, 1991, p.81).

Bradley (1993) found that over time positive selfmodeling can have a positive effect on the performance of basketball players. Fetlz (1982) reported that participants who had twelve demonstrations had higher form scores than the control group on a Bachman-ladder test. Hall and Erffmeyer (1983) reported an improvement in foul shot performance when modeling with visuo-motor behavior rehearsal (VMBR) was used. The results showed that there was a significant improvement difference for the group who received modeling compared with the group that did not (Hall \& Erffmeyer, 1983). Gray (1990) showed that modeling combined with visuo-motor behavior rehearsal can lead to improvements in racquetball performance.

McCullagh and Weiss (2001) also indicate the importance of modeling on the confidence of athletes noting, "It is apparent that modeling can indeed have profound effects not only on performance but also on psychological variables (e.g., anxiety, fear, affect) that may impact physical activity patterns" (p.212).

McCullagh and Weiss (2002) again note the important relationship between modeling, selfefficacy, and sport performance. " Thus, observational learning and self-efficacy go hand in hand. Observational learning is a key source of efficacy beliefs that, in turn, influence thoughts, emotions, and behaviors" (McCullagh \& Weiss, 2002, p.134)

This result prove the second hypothes of the study. That there are statistical significant difference of skill performance level and cognitive achievement variables between the experimental group and the control group on the post-test in favor of the experimental group.

\section{Conclution:}

The results of this study showed that there was significant improvement difference for the group who received self-modeling compared with the group that did not. In conclusion, it can be said that the use of the positive self Model through the instructional program led to positive results in improving skill performance level and cognitive achievement in wrestling.

\section{practical implications}

So there are some practical implications according to the outcome of this study as follow:

- The positive self model can be used to promote learning in physical contexts.

- The individual sports especially can make use of the positive self model in the instructional process.

- The instructional programme of the study maybe helpful in designing other programme or instructional strategies.

- Modern techniques of instruction technology must take place in learning physical education activities.

- The positive self model can be also useful in training players especially in the compound technical skills.

\section{Recommendations for Future Research :}

The outcome of this study can make some future research directions as follow :

- Studies on other sample of different ages.

- Using the positive self model to solve some instructional problems such as learning difficulties. 
- Performing studies about improving the making and preparation of positive self model.

- Finding out the difference between the individual and team sports in using positives self model.

\section{References}

Bradley, R.D. (1993). The use of goal-setting and positive self-modeling to enhance self-efficacy and performance for the basketball free-throw shoot (Doctoral Dissertation, University of Maryland, 1993). Dissertation Abstracts International, 54, 1723.

Copper , E. (2003). Teaching and Learning Physical Education in Secondary Schools , Wm . C. Brown, Company Publishers.

Dowrick, P.W. (1999). A review of self-modeling and related interventions. Applied and Preventive Psychology, 8, 23-39.

Feltz, D.L. (1982). The effects of age and number of demonstrations on modeling of form and performance. Research Quarterly for Exercise and Sport, 53, 291-296.

Gable, D., (1999). Couching Wrestling successfully, Human Kinetics, champalgn, IL.

Gray, S.W. (1990). Effect of visuomotor rehearsal with videotaped modeling on racquetball performance of beginning players. Perceptual and Motor Skills, 70, 379-385.

Hall, E.G., Erffmeyer, E.S.(1983). The effect of visuo-motor behavior rehearsal with videotaped modeling on free throw accuracy of intercollegiate female basketball players. Journal of Sport Psychology, 5, 343-346.

Halliwell, W. (1990). Providing sport psychology consulting services in professional hockey. The Sports Psychologist, 4, 369-377.
Jensen, C.R. \& Fisher, A.G.(1979).Scientific Basis of Athletic conditioning, $2^{\text {nd }}$ ed., Philadelphia, Lea \& Febiger.

Jensen, C.R. Hirst, C.C.(1980).Measurement in Physical education and athletics, New Yourk, Macmillan Publishing Co., inc..

Jerman, T. \& Hanely, R. (1983). Wrestling for Beginners, $1^{\text {st }}$ ed., Comtemfortery Books. Inc., Chicago.

Johnson, D.A.(1991).Wrestling Drill Book, Leisure Press, Champaign Ilinois.

Keith, A.;(1990). Successful wrestling, Coaches Guide to teaching Basic to advanced skills, leisure press, champalgn, IL.

Knapczyk, D. (1991). Effects of modeling in prompting generalization of student question asking and question answering. Learning Disabilities Research and Practice, 6, 75-82.

McCullage, P. \& Veiss, M.R. (2001). Modeling: Considerations for motor skill performance and psychological responses. In R.N. Singer, H.A. Hausenbals \& C.M. Janelle (Eds.), Handbook for sport psychology (pp.205-238). New York: Wiley $\&$ Sons.

McCullage, P. \& Weiss, M.R. (2002). Observational learning: The forgotten psychological method in sport psychology. In J. L. Van Raalte \& B.W. Brewer (Eds.) Exploring sport and exercise psychology (p. 131-149). Washington, D.C.: American Psychological Association.

Vealey, R.S., Hayashi, S.W. Garner-Holman, M.\& P. Giaacholli (1998). Sources of sport-confidence: Conceptualization and Instrument Development. Journal of Sport and Exercise Psychology,20, 5480.

Weinberg, R, Grove, R. \& Jackson, A. (1992). Strategies for building self-efficacy in tennis players: A comparative analysis of Australian and American coaches. Th sport Psychologist, 6, 3-13 